\title{
Living under silence: Untold stories of sexual violence
}

\section{By Lily Crist}

Lessons from female refugee victims of conflict-related sexual violence in Kosovo and the application of forensic science to the care of populations in Vancouver.

G rowing up, I would hear stories that adults told, stories that kept me awake at night. They puzzled me by the complexity of unknown words that were foreign to my understanding and that wrapped me in wonder and awe. If you made yourself invisible to the world of adults or pretended to play and not pay attention while they shared their stories, you could learn much about their world. Whoever says that kids do not understand what is going on in the world of adults is mistaken.

As in Ancient Greece and in many Mediterranean cultures, the gynaeceum was a closed realm for women where they could be free to be together and share stories. The gynaeceum was often a room or place in a house where women, married and unmarried, enslaved and free, could come together and spend time with each other. For me, as with the gynaeceum, any gathering of women has brought to light many new words and ideas. Over time, a particular geography started to emerge as I learned about how men and women interacted and how gender expectations based on traditions, customs and morality impacted me and everyone around me. I learned as a child that some stories needed to remain untold for fear of retaliation or worse: they were so toxic that they could destroy everything around. Sometimes these stories emerged in fragments, incomplete and mysterious, then spread into every area of one's life. What happens when the truth is so unbearable to tell and, to continue living, one has to bury one's story deep inside oneself? What happens when there is no one to talk to?

Over the decades, it has been very important for me to understand the barriers a victim faces when she chooses to share her story-or when she is unable to do so-and the best ways of caring for victims of sexual violence. The focus of this paper will be the female refugee victims of Kosovo and the care provided to them in particular. In examining their situation, I hope to learn more about the challenges to accessing care and the ways in which, for this specific population, access to adequate care can be improved.

This paper will bring to light some approaches and responses to the care of these female refugee victims of conflict-related sexual violence and the role of forensic health sciences in that care. The focus will be on a specific group: ethnic Albanian women from the Kosovo region before and during the Balkan wars, mostly female refugee victims of sexual violence. Sexual violence can indeed be conflict-related, as it was during the Balkan wars. Many parallels can be drawn with other women in other war zones where military forces have used sexual violence as a tool against civilian populations. According to United Nations Security
Council Resolution 1820, S/RES/1820 (2008), from June 19, 2008 , sexual violence is conflict-related "when used or commissioned as a tactic of war in order to deliberately target civilians or as part of a widespread or systematic attack against civilian populations." The resolution notes that "civilians account for the vast majority of those adversely affected by armed conflict; (... ) women and girls are particularly targeted by the use of sexual violence, including as a tactic of war to humiliate, dominate, instill fear in, disperse and/or forcibly relocate civilian members of a community or ethnic group."

Trying to explain how a particular society functions and relates to female victims of sexual violence is complex and might not be possible in this limited format. Nevertheless, we can look at some reasons why victims of rape in this specific context do not disclose their situation to healthcare providers or law-enforcement officers and we will look afterwards at strategies to respond to the needs of female refugees. Focusing on the care needed by female victims of this conflict in the Balkans can bring to light some of the directions that healthcare providers (forensic nurses, FNE) have taken or can take. Canada has welcomed many refugees from war zones over the years, and a better understanding of female refugees and their needs can have a positive impact on both healthcare providers and their patients. In the past, Canada has been directly involved on the ground in Kosovo by providing military, medical and civilian teams.

A short anthropological introduction to establish the context of the conflict and a brief description of Albanian society and views on female victims will help to better comprehend some of the barriers to accessing care. First, some background information to better understand the Albanian culture and traditions in Kosovo. As soon as Slobodan Milošević came to power in the former Yugoslavia in the 1990s, even before the start of war in the Balkans, the ethnic Albanian population of the region of Kosovo was living under duress. Healthcare providers, teachers and many ethnic Albanians of the region lost their jobs merely because they were Albanian. Schools, universities, hospitals and all governmental organizations run by ethnic Albanians for their populations were closed and this for the subsequent ten years, until the end of the conflict in the Balkans. Ethnic Albanian healthcare providers in local hospitals were replaced by Serbs, whom the local Albanian population highly distrusted. In this context, there emerged a parallel illegal society that tried to resist the occupation. Prenatal care was almost nonexistent for many women and, for an Albanian woman, giving birth was a source of fear and danger. In this context, women internalized their concerns. They refrained from sharing them with healthcare providers whom they distrusted.

Violence against civilian populations increased in Kosovo and culminated during the war in 1998-1999. In the article 
"How Long Can You Keep a Secret? For Kosovo's Wartime Rape Victims, the Answer is Maybe Forever" from Radio Free Europe/Radio Liberty, rapes committed by paramilitary Serbian forces were a way to terrorize, humiliate and stigmatize women (Rames, 2013). The war eventually ended, but for the survivors the hardships continued. Notably, the attitudes toward victims of sexual violence were very negative. Indeed, Albanian society has certainly sustained some egregious beliefs. One of them is that an Albanian woman's honour is more precious than her life and that a "good" woman must kill herself after a sexual assault to prevent bringing shame to her family and clan. In this manner, stigmatization has an impact on the ability — and opportunityfor victims to seek treatment.

The Albanian society of the Kosovo region was a rigid and codified male-dominated one, where women passed from the authority of their fathers, brothers and other male relatives to that of their husbands' or in-laws' families. The prevalence of the old code of traditional laws, the 15th-century Kanun that controlled matters pertaining to families, marriage, properties, clan life, etc., impacted the gender relations and views on victims of sexual and domestic violence. As they fled, many Albanian families from Kosovo were persecuted and displaced to neighbouring countries or killed during the war. Among female Albanian refugees, stories of violence and sexual violence were not shared with the outside world or even with spouses or other family members, for fear of abandonment, retaliation or rejection by their communities. Sexual violence was and is still a taboo subject in this society. Since August 2013, the Kosovo Rehabilitation Centre for Torture Victims (KRCT) has worked on a project called Empowering Women Victims of Sexual Violence and Torture during Conflict in Kosovo to help victims come forward and receive compensation and medical counselling. In the study commissioned by the United Nation called Healing the Spirit: Reparations for Survivors of Sexual Violence Related to the Armed Conflict in Kosovo (Rames, 2013), specific reasons for victims not disclosing incidents of sexual violence included the fear of stigmatization and related social consequences. Indeed, by coming forward, they would be ostracized by the whole family and their community; their spouses and families would abandon them and view them as pariahs. In addition, a key reason for which victims of sexual violence did not disclose their experiences was the shame that they felt. According to the article "Tracking Gender-Based Human Rights Violations in Postwar Kosovo" from the American Journal of Public Health, the fear of stigmatization was compoundedand still is to this day-by the lack of support services as a major obstacle towards disclosure of sexual violence (Desai \& Perry, 2004). In addition to the regular barriers to access care, the victims of this conflict faced a greater stigma from their communities and families. Healing the Spirit (Rames, 2013) also mentions the lack of healthcare providers after the conflict due to their execution during the war and the overall destruction of infrastructure.

From this conflict emerged some important new ways to care for female refugee victims of sexual violence. One of the approaches mentioned in the Guttmacher Report on Public Policy from 1999 was the distribution of reproductive health kits to the Kosovar refugees as reports started to emerge of systematic rape of Albanian women as they were leaving their country
(The Guttmacher Report on Public Policy, 1999). In her 2014 article from Nursing entitled "Female Refugees: Sensitive Care Needed," Elizabeth Heavey provides a better understanding of nursing challenges and helpful strategies to care for female refugees. Patients who have experienced sexual violence during wars can show signs of post-traumatic stress disorder (PTSD) and use disassociation "as a coping mechanism." In the article, Heavey describes some of the health-risk factors observable among PTSD victims. They range from cardiovascular disorders to suicide. As she notes, "PTSD doesn't just affect mental health." According to Linda E. Ledray et al. (2011) in Medical Response to Adult Sexual Assault, reactions to traumatic events like sexual violence can take many forms: physical, emotional, cognitive and behavioural (pp. 215-216).

Heavey mentions that nurses can play a key role in helping victims. In her words, "Clear and compassionate communication is critical to optimize nursing and medical care." When patients are familiar with healthcare providers and feel safe with them, there is a greater chance for disclosure. Such is what Bridgid McGowan said in a guest lecture at the British Columbia Institute of Technology on February 17, 2015 in the context of a course entitled Sexual Assault Nurse Examiner Core Education: Theoretical Aspects. In her presentation, McGowan described how forensic and other nurses can help victims of trauma by giving the patient control over the medical process, creating a feeling of predictability and preventing the loss of safety. This course was taught by Aimee Falkenberg (RN FNE BSN SANE-A) (Falkenberg, 2018). In an exchange with me, she shared some of the wisdom and experience that she had acquired from her work with victims of sexual assault and trafficking. She brought up some important points with regard to victim assistance. Notably, she advised us not to make a survivor repeat her story to too many people, as it is difficult enough to share the story only once. Falkenberg put the emphasis on empowering the survivor by letting her know how proud you are that she came in looking for help. She also discussed the many barriers for victims trying to access care in the wake of sexual violence. Very few victims come to get help, so it becomes paramount to support those who do. She added that, as nurses and medical staff, we need to be mindful and to refrain from judging or deciding if sexual violence has occurred or not. We are there to provide the survivor with medical needs relevant to her stated history and to offer a path towards forensic nursing services, in this manner allowing the survivor to be in control at all times. Falkenberg also shared a key element to any interaction with victims, the need to listen. When we listen, we show compassion, and a victim is more likely to open up, sharing an enlightening anecdote or story.

Forensics does not only work within nursing. It can also apply to social interventions like those that occur at La Boussole, a francophone nonprofit organization in Vancouver that, inter alia, helps female refugees integrate into Canadian society. For a year, I was the executive director of La Boussole. Every week, francophones newly arrived in the city reached out to us. They required help in obtaining housing and work, counselling, financial advice and interpretation services. Our clients faced many barriers when it came to accessing healthcare and other services. Indeed, the languages spoken by the refugees whom we dealt with on a regular 
basis were not necessarily understood by health professionals in British Columbia. As a consequence, our clients could have a hard time in making themselves understood and more generally in receiving the physical and mental care that they needed.

In this organization, employees accompany their clients to various institutions, including medical doctors' offices and hospitals, acting as interpreters and guides in their interactions with medical personnel. Such help is important, because refugees to Vancouver, particularly the female ones, face unique obstacles. For example, there might not be any spaces in transition houses for them, or there might not even be any transition houses in their neighbourhoods. They might not know how to contact such places or be able to interpret the rules once they have been admitted. In addition, their experiences in their countries of origin might cause them to be suspicious of law enforcement and the judicial system.

At La Boussole, the employees have the knowledge and experience required to aid refugees arriving in the city. They can listen impartially to refugees and act in accordance with well-established protocols in social work. Each employee brings her personal touch and especially her life experiences to bear when she assists refugees, guiding them through the bureaucratic maze that sometimes separates them from adequate health care. Our employees can adapt their interventions to each client on the basis of their empathy towards those whom they help, their knowledge of the community and their various sociocultural reference points. Their capacity to adapt their approaches in accordance with different clients' needs is essential, as those needs can vary tremendously. A client's personal characteristics are a factor, as well as how recent, immersive and severe their experiences of war and conflict have been. In the recent past, at La Boussole, we assisted women, often accompanied by their children, who had escaped from violent situations in their home countries, where sexual assault was an all-too-common practice. Some clients have also fled violence experienced in Canada.

The personnel at La Boussole accompanies clients for their medical appointments. In this context, the staff members do not merely act as interpreters on behalf of the clients. Through their moral support and guidance, they assist in making client interactions with the medical personnel as smooth and painless as possible. While respecting their clients' autonomy, they endeavour to ensure that client views are expressed and client preferences are defended. They also assist clients in following through with regard to a medical doctor's advice, prescriptions and attendance at follow-up appointments with the doctor or specialists.

My own educational and professional experience has prepared me well for supporting and guiding clients and for dealing with the challenges and even crises that arise from time to time. In particular, my health-science education at the British Columbia Institute of Technology has given me the knowledge and confidence to support-as best I can-women who have escaped from conflict zones and interpersonal violence. When someone called or showed up at La Boussole and felt comfortable about sharing her experiences with me, it was important for me to listen attentively, to show empathy and to observe telling details that the visitor was sharing. Doing so could help me establish a course of action suited to her needs. Indeed, in paying close attention to her life story and listening to what she emphasized, I could quickly develop a plan calibrated to her needs.

Forensic health sciences in relation to nursing have evolved over the recent past in a manner that can provide clarity with regard to epidemiological issues such as violent crimes (from sexual assault to murder), trauma, negligence and suicide, to name only a few. Nursing-related forensics are highly relevant in connection with those individuals so frequently encountered in our society, in drop-in clinics, emergency wards and elsewhere.

More broadly, intervention has many facets as it involves a diversity of experts working in interrelated fields. People who aid victims work in law enforcement, justice, medicine and social work, among other areas. A background in forensic health sciences can assist people in all of these areas. It certainly has helped me. Forensics contributes to a better understanding of signs of violence-which can differ with regard to a victim's characteristics, including notably her age - and to an improved ability to ask the right questions. To succeed in assisting female victims of mental or physical abuse or violence, one needs to be curious and openminded. One needs also to document and preserve evidence of harm. Familiarity with forensics can enable a healthcare professional to be more efficient in assisting survivors of sexual assault, violent crimes or other forms of abuse. In this regard, certain hospitals in the Lower Mainland offer nursing services adapted to the needs of victims of sexual abuse (Sexual Assault Nurse Examiner-SANE).

At BCIT, professor Sheila Early taught me that an inquisitive mind, active listening skills and a duty to care are at the heart of forensic nursing and that all of us have a role to play in putting an end to violence in society, be it in a clinical setting or in conversations among friends. Professor Early, in her teachings, often emphasized that a forensic nurse examiner needs to be perceptive, constantly questioning circumstances with the goal of getting at the truth in order to support victims as effectively as possible. Our clients do not always state in so many words what is troubling them, but an educated and experienced listener can often get at the heart of their problems. In this regard, female refugees who have survived sexual assault and other forms of violence might consult with medical practitioners for problems unrelated to their traumatic experiences while displaying symptoms of posttraumatic stress disorder including hypervigilance. A perceptive professional can detect these symptoms and adapt her treatment in accordance with her interpretation of the situation.

Unfortunately, the experiences of Albanian refugees from Kosovo who have settled in Canada are not exceptional. Facing the same challenges are many female refugees from other zones of hardship and conflict around the world, including refugee camps, which present their own dangers. In addition, one can apply one's knowledge in forensic health sciences to include working with people escaping difficult situations within Canada as well, whether they live in remote communities or disadvantaged urban and suburban neighbourhoods in larger cities. But the number of female refugees who have arrived in Canada from outside the country remains high, numbering 28,689 in 2016 
alone (Government of Canada, 2017). Each refugee brings with her specific traumas and faces particular challenges.

The work of forensic nurse examiners and culturally sensitive approaches among all people who assist refugees are two ways to help with the healing process. For female survivors from Kosovo, access to justice and reparation programs are among the tools developed by the UN Secretary-General in 2014 as part of his Guidance Note on Reparations for Conflict-Related Sexual Violence. In the words of Siobhan Hobbs, Gender Adviser with the UN Women's Project Office in Kosovo, "That was really an attempt by the head of the UN to pool together the lessons learned, not just from the specific field of sexual violence, but also from reparations in general."

The devastation of a war continues long after it has ended and many initiatives and government programs are put in place to help victims of conflict, rebuild infrastructure and create a more just society, one in which there are no gender-based inequalities or violence. However, in a report from the UNHCR, the postwar situation of Albanian women is perceived to have deteriorated and, moreover, some young women from lower socioeconomic backgrounds have become victims of human trafficking (Baker \& Hilde, 2002).

Some stories might not have been told yet, or they might be buried under a heavy wall of silence. Since childhood, I have continued to listen for such stories, now more in a quest for moments where victims find the courage to express their innermost feelings. In many such cases, it is their silences that are most eloquent. For them, to revisit the evils that war and conflict can bring is like opening a modern-day Pandora's Box. However, at the very least, female refugees from Kosovo who have experienced sexual violence will find at the bottom of the Box one last thing that can help them to rebuild their lives: hope. In Albanian, they call it "Shpresē" and little girls are sometimes named "Shpresa," the one who has hope.

\section{Author's take-away}

1. Clear and compassionate communication is critical to optimize nursing and medical care.

2. Nurses can help victims of trauma by giving the patient control over the medical process, creating a feeling of predictability and preventing the loss of safety.

3. Empowering the survivors by letting her know how proud you are that they came in looking for help

4. We need to be mindful and to refrain from judging or deciding if sexual violence has occurred or not

5. A key element to any interaction with victims is the need to listen.

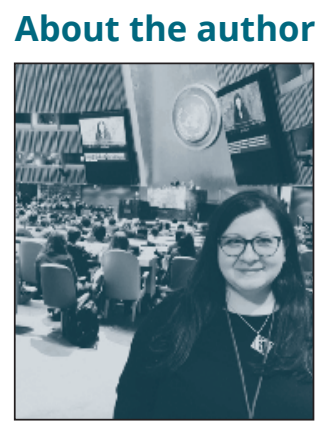

As president of the Alliance des femmes de la francophonie canadienne, Lily Crist works to represent Francophone women in Canada in the nine provinces and three territories where they are linguistic minorities. She has been involved in the women's movement for the past 22 years. Ms. Crist has studied as an adult educator, a counsellor, and in Forensic Health sciences, leading her to be an experienced and knowledgeable supporter of victims of sexual violence. Ms. Crist helped to develop a pilot education project that brings information about healthy relationships, gender, and diversity to Francophone secondary schools. Working with La Boussole, Ms. Crist is part of the only Francophone organization working to combat homelessness and offering services to those living in poverty through a food bank, community courses, supporting mental health initiatives, and creating safe and open Francophone spaces in Vancouver. Additionally, Ms. Crist helped to establish the francophone crisis hotline Inform'elles, which offers support to French-speaking women living in Anglophone regions. As of September 2018, she is pursuing a Bachelor in Nursing Sciences at Vancouver Community College in Vancouver.

\section{REFERENCES}

Baker, J., \& Hilde H. (2002, November). The Kosovo Women's Initiative: An Independent Evaluation. Geneva, Switzerland: Evaluation and Policy Analysis Unit, United Nations. Retrieved from: http://www.unhcr.org/cgibin/texis/vtx/home/opendocPDF. pdf? docid=3db019784\&query=Kosovo

Desai, S., \& Perry M.J. (2004). Tracking Gender-Based Human Rights Violations in Postwar Kosovo. American Journal of Public Health, 94(8), 1304-1307. Retrieved from: http://www.ncbi.nlm.nih. gov/pmc/articles/PMC1448442/

Falkenberg, A. (2018, August 13). Follow up on Sexual Assault Nurse Examiner Core Education: Theoretical Aspects. Burnaby, BC: BCIT.

Government of Canada. (2017, November 1). 2017 Annual Report to Parliament on Immigration [not available]. Retrieved from https://www.canada.ca/en/immigration-refugees-citizenship/ corporate/publications-manuals/annual-report-parliamentimmigration-2017.html

Heavey, E. (2014). Female Refugees: Sensitive Care Needed. Nursing, $44(5), 28-34$.

Hobbs, S. (2016, August). Path to justice for survivors of Kosovo's sexual violence: Q\&A with Siobhan Hobbs.
Retrieved from: http://eca.unwomen.org/en/news/ stories/2016/08/q-and-a-with-siobhan-hobbs

Ledray, L.E., Burgess, A.W., \& Giardino, A.P. (2011). Medical Response to Adult Sexual Assault: A Resource for Clinicians and Related Professionals. St. Louis, MO: STM Learning, Inc.

McGowan, B. (2015, February 17). Sexual Assault Nurse Examiner Core Education: Theoretical Aspects. Burnaby, BC: BCIT.

Rames, V.S. (2013). Healing the Spirit: Reparations for Survivors of Sexual Violence Related to the Armed Conflict in Kosovo. Office of the United Nations High Commissioner for Human Rights. Retrieved from: http://www.ohchr.org/Documents/Issues/ Women/WRGS/PeaceAndSecurity/StudyHealingTheSpirit.pdf

The Guttmacher Report on Public Policy. (1999, June). Reproductive Health Kits Provided by UNFPA to Kosovar Refugees. The Guttmacher Report on Public Policy, 2(3), 12-13.

United Nations Security Council. (2008, June 19). Resolution 1820. Retrieved from: http://www.securitycouncilreport.org/atf/ cf/\%7B65BFCF9B-6D27-4E9C-8CD3-CF6E4FF96FF9\%7D/ CAC\%20S\%20RES\%201820.pdf 